\title{
Targeting mTOR by CZ415 Inhibits Head and Neck Squamous Cell Carcinoma Cells
}

\author{
Jing Xie ${ }^{\mathrm{a}}$ Quan Lib Xi Ding ${ }^{\mathrm{a}}$ Yunyun $\mathrm{GaO}^{\mathrm{a}}$ \\ aDepartment of Stomatology, The First Affiliated Hospital of Wenzhou Medical University, Wenzhou, \\ ${ }^{b}$ Center of Stomatology, The second affiliated hospital of Soochow University, Suzhou, China
}

\author{
Key Words \\ Hnscc $・$ MTOR $・$ CZ415 • Beclin-1 • Autophagy
}

\begin{abstract}
Background/Aims: mTOR is an important therapeutic target for human head and neck squamous cell carcinoma (HNSCC). The current study tested the anti-HNSCC cell activity by a mTOR kinase inhibitor CZ415. Methods: HNSCC cells were treated with CZ415. Cell death was tested by lactate dehydrogenase (LDH) assay and MTT assay. Cell proliferation was tested by BrdU ELISA assay and $\left[\mathrm{H}^{3}\right]$ thymidine incorporation assay, with apoptosis assayed by the TUNEL staining. A Western blotting assay was applied to test autophagy-associated proteins, mTOR and signalings. The nude mice xenograft model was established to study CZ415-mediated anti-tumor activity. Results: In established (SCC-9, SQ20B and A253 lines) and primary human HNSCC cells, CZ415 efficiently inhibited cell survival and proliferation. CZ415 blocked mTORC1/2 activation and inhibited ERK in HNSCC cells. CZ415 provoked feedback autophagy activation. Conversely, autophagy inhibitors (3-methyladenine and chloroquine) or Beclin-1 shRNA sensitized CZ415-induced HNSCC cell death. In vivo, CZ415 gavage inhibited SCC9 tumor growth in nude mice, showing higher efficiency against Beclin-1-silenced tumors. Conclusion: CZ415 inhibits HNSCC cell growth in vitro and in vivo. Inhibition of autophagy can further sensitize CZ415 against HNSCC cells.

\section{Introduction}

Head and neck squamous cell carcinoma (HNSCC) is a heterogeneous family of carcinomas [1-3]. HNSCC is often diagnosed at late- or advanced-stage [1-4]. The lack of effective treatment can cause HNSCC progression [1-4]. Deregulation of mTOR (mammalian target of rapamycin) signaling plays a critical role in HNSCC progression [5-7]. mTOR activation promotes a number of key cancerous behaviors [8-11]. Therefore, mTOR is an important therapeutic target for HNSCC [5-7]. Our previous study has demonstrated that GSK1059615, a novel PI3K-mTOR dual inhibitor, inhibited HNSCC cell growth in vitro and in vivo [12].
\end{abstract}




\section{Cellular Physiology Cell Physiol Biochem 2018;46:676-686

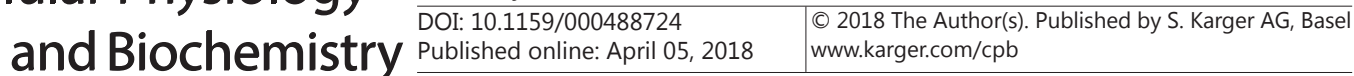 \\ Xie et al.: CZ415 Inhibits Human HNSCC Cells}

mTOR signaling is mediated through two multiple-protein complexes, including mTOR complex 1 (mTORC1) and mTOR complex 2 (mTORC2) [8]. mTORC1 is composed of mTOR, PRAS40, Raptor, and mLST8 $[13,14]$. Its activity can be inhibited by rapamycin and its analogs [8]. mTORC1 phosphorylates two major substrates, p70S6K1 (S6K1) and eIF4Ebinding protein 1 (4E-BP1) $[8,15]$. mTORC2 is primarily formed by mTOR, Rictor and mSin 1 $[8,13,14]$. mTORC2 is the upstream kinase of AKT (at Ser-473) $[8,13,14]$. CZ415 is a highlyselective, extremely potent and orally-available mTOR kinase inhibitor [16]. It has excellent selectivity against mTOR [16]. Its activity in human HNSCC cells has not been tested.

\section{Materials and Methods}

\section{Chemicals and reagents}

CZ415 was provided by Dr. Yin [17]. Autophagy inhibitors 3-methyladenine (3-MA) and chloroquine (Cq) were purchased from Sigma (Shanghai, China). Puromycin was also obtained from Sigma. Cell culture reagents were provided by Gibco (Suzhou, China). OSI-027, rapamycin and everolimus (RAD001) were purchased from Selleck (Shanghai, China). Antibodies for phosphorylated ("p")-AKT (Ser-473) (9271), p-AKT (Thr-308) (9275), AKT1 (2967), p-p70 S6 kinase 1 (S6K1, Thr 398, 9209), S6K1 (9202), p-p44/42 MAPK (ERK1/2) (9102) and ERK1/2 (9102), Beclin-1 (3495), ATG-5 (12994), ATG-7 (8558), p62 (5114), and LC3B-I/II (12741), as well as cyclin D1 (2922), cyclin B1 (4138) and $\beta$-actin (4970) were all purchased from Cell Signaling Tech (Shanghai, China). The $\beta$-tubulin antibody (T2200) was obtained from SigmaAldrich (St. Louis, MO).

\section{HNSCC cell lines}

As described [12], established HNSCC cell lines, SCC-9, SQ20B and A253, were from Dr. Cui's group [18], and cells were maintained in FBS-containing DMEM medium [18].

\section{Primary culture human cancer cells and epithelial cells}

The detailed protocols of primary culture of human oral cavity carcinoma (OCC) cells and oral (cavity) epithelial cells were described in our previous study [12]. Four lines of primary OCC cells ("OCC1-4") and two lines of oral epithelial cells ("Oepi1-2") were established [12]. The protocols were approved by the Institutional Ethics Committee and Internal Review Committee of authors' institutions, and were conducted according to World Medical Association (Declaration of Helsinki). The privacy rights of human subjects must always be observed.

\section{MTT assay}

To test cell viability, the routine MTT (Sigma) assay was performed with manufactory's recommendation $[12,19]$. MTT OD at $590 \mathrm{~nm}$ was recorded.

\section{Clonogenicity assay}

SCC- 9 cells $\left(1 \times 10^{4}\right.$ per $10-\mathrm{cm}$ dish $)$ were originally plated in $0.5 \%$ agarose-containing complete medium. After applied CZ415 treatment of 10 days, the survival SCC- 9 colonies were manually counted.

Lactate dehydrogenase (LDH) assay

Release of LDH to the conditional medium is a characteristic marker of cell death. We utilized the twostep LDH assay kit (Takara, Tokyo, Japan) [20] to examined medium LDH content [12, 20].

\section{In vitro proliferation assay}

Test of cell proliferation by the BrdU ELISA assay or the $\left[\mathrm{H}^{3}\right]$ thymidine incorporation assay was described in detail in our previous studies $[12,15]$. The value of treatment groups was always normalized to that of the untreated control group.

TUNEL assay

The terminal deoxynucleotidyl transferase dUTP nick end labeling (TUNEL) assay allows quick and easy demonstration of cell apoptosis. In line with our previous study [12], The TUNEL In Situ Cell Death 


\section{Cellular Physiology Cell Physiol Biochem 2018;46:676-686

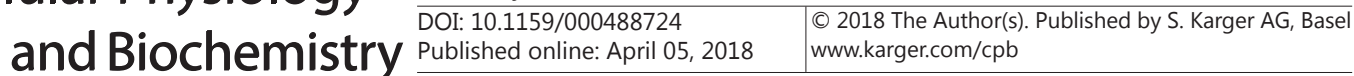 \\ Xie et al.: CZ415 Inhibits Human HNSCC Cells}

Detection Kit (Roche, Shanghai, China) was utilized to stain nuclei of apoptotic cells. TUNEL ratio of 200 cells per treatment was recorded.

Western blotting assay

Following the applied treatment, cells or tumor tissues were lysed via RIPA lysis buffer (Biyuntian, Shanghai, China). For each treatment, thirty $\mu \mathrm{g}$ of lysate proteins per lane were separated by the SDS-polyacrylamide gel electrophoresis (PAGE) gel (10-12.5\%), which were then transferred to the polyvinylidene fluoride (PVDF) membrane (Millipore, Shanghai, China). After blocking in 10\% milk, the blot was incubated with designated primary and corresponding secondary antibodies [21]. The ECL reagents (Amersham Biosciences, Shanghai, China) were employed to detect antibody-antigen binding. The total gray of each band was quantified via Image J software (NIH).

\section{shRNA knockdown of Beclin-1}

The two verified Beclin-1-targeting lentiviral shRNAs ("a/b", with non-overlapping sequence), as well as the scramble control lentiviral shRNA were provided by Dr. Jiang [22]. The lentiviral shRNA was added to cultured SCC- 9 cells (50\% confluence in basic medium) for 12 hours. Cells were then subjected to puromycin (5 $\mu \mathrm{g} / \mathrm{mL}$, Sigma) selection for additional 6 passages. Beclin-1 expression in the stable cells was tested by Western blotting assay.

Tumor xenograft assay

Five millions of SCC-9 cells or primary human OCC cells per mouse were inoculated s.c. into the female nude mice (5-6 week age, 18.2-19.1 grams in weight). Within 2-3 weeks, xenograft tumors were established, and tumor volumes were around $0.1 \mathrm{~cm}^{3}$. The mice were then randomly assigned into groups as mentioned in the text ( $\mathrm{n}=10$ per group). Tumor volume was measured once every week as described [12]. Estimated daily tumor growth was calculated according to our previous study [12]. The animal procedures were approved by the Institutional Animal Care and Use Committee (IACUC) of authors institutions and comply with the National Institutes of Health guide for the care and use of Laboratory animals.

\section{Immunohistochemistry (IHC) staining}

The detailed protocol of IHC staining was described in published studies [23]. Tumor tissues were first fixed, embedded in paraffin, and cut into the $4 \mu \mathrm{m}$ sections. The paraffin sections were deparaffined and incubated with $3 \%$ hydrogen peroxide. Then, the sections were blocked, incubated with anti-S6K1 antibody (1:100) and horseradish peroxidase (HRP)-coupled secondary antibody (Santa Cruz). The peroxidase activity was visualized through the 3-amino-9-ethyl-carbazol (AEC) and MAYER'S method (Merck) [23].

\section{Statistical analysis}

The results of one whole set of experiment were shown. Results were compared by one-way analysis of variance (ANOVA) followed by Turkey's test. Values of $p<0.05$ were considered as statistically significant. Experiments in Figs 1-5 were repeated at least three times, and similar results were obtained each time.

\section{Results}

\section{CZ415 inhibits HNSCC cell survival}

First, SCC-9 human HNSCC cells [12] were treated with gradually-increased concentrations of CZ415 (from 1 to $300 \mathrm{nM}$ ). MTT viability assay results in Fig. 1A show that CZ415 dose-dependently inhibited SCC-9 cell survival (MTT OD). CZ415 IC-50 was close to 30-100 nM (72-96 hour treatment) (Fig. 1A). At a low concentration (1 nM), CZ415 was however ineffective (Fig. 1A). CZ415 displayed a time-dependent response in inhibiting SCC-9 cell viability (Fig. 1A). It requires at least 48-72 hours to exert significant cytotoxicity (Fig. 1A). The clonogenicity assay shows that CZ415 at 10-300 nM significantly reduced the number of viable SCC-9 colonies (Fig. 1B). Additionally, CZ415 induced LDH release in SCC-9 cells, confirming cell death (Fig. 1C).

SQ20B and A253 HNSCC cells were treated with CZ415 as well. A MTT assay shows that CZ415 (100 nM, 72 hours) was cytotoxic to these cells (Fig. 1D). Conversely, the same CZ415

\section{KARGER}


Fig. 1. CZ415 inhibits HNSCC cell survival. The established HNSCC cells (SCC-9, SQ20B and A253) (A-D, F), the primary human oral cavity carcinoma (OCC) cells ("OCC1-4 lines") (E) or the oral epithelial cells ("Oepi1/2 lines") (D) were treated with designated concentration of CZ415 ("CZ"), rapamycin ("Rap"), RAD001 ("RAD") or OSI-027 ("OSI"), cells were further cultured for indicated time, and cell survival/death were tested by assays mentioned in the text. "C" stands for untreated control group (Same for all Figs). For each assay, $n=5$. Bars stand for mean \pm standard deviation (S.D.,

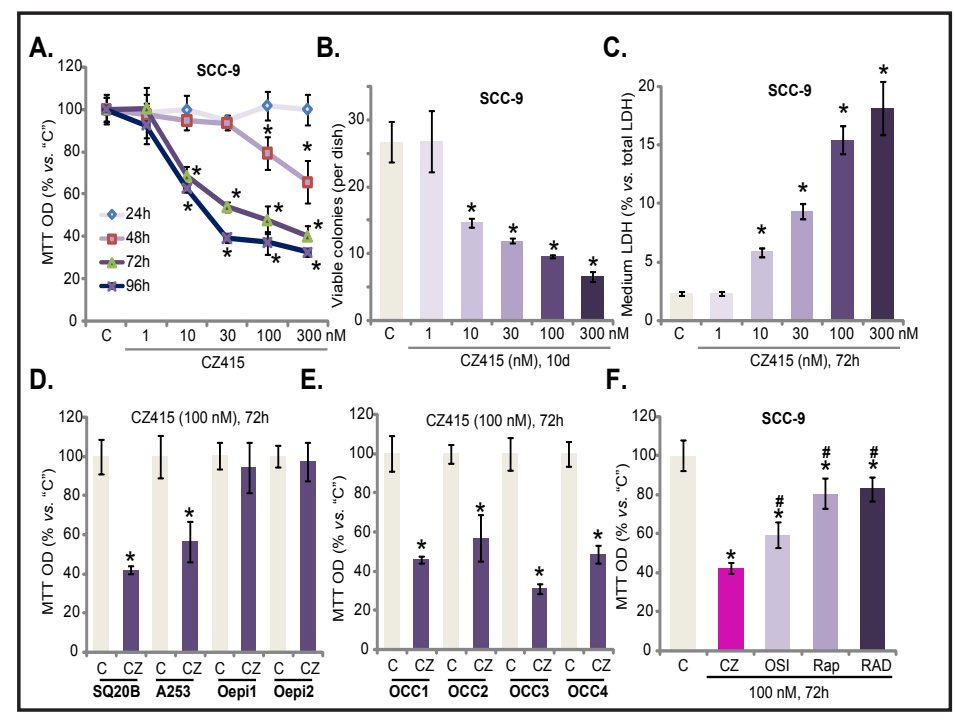
Same for all Figs). ${ }^{*}$ p $<0.05$ vs. group "C". "p<0.05 vs. CZ415 only (F). Experiments in this Fig. were repeated three times, and similar results were obtained.

treatment $(100 \mathrm{nM}, \quad 72$ hours) was non-cytotoxic to the oral epithelial cell ("Oepi1/2" [12]). CZ415's potential effect in the primary human oral cavity carcinoma (OCC) cells was tested. As described previously [12], four lines of primary OCC cells (namely "OCC1/2/3/4") were established. Following treatment of CZ415 (100 nM, 72 hours), a MTT assay shows that CZ415 decreased viability of the primary OCC cells (Fig. 1E). The MTT assay results in Fig. 1F show that CZ415 was significantly more potent in inhibiting SCC-9 cell viability than the same concentration of rapamycin and RAD001, two mTORC1 inhibitors [24]. CZ415 was even more efficient than

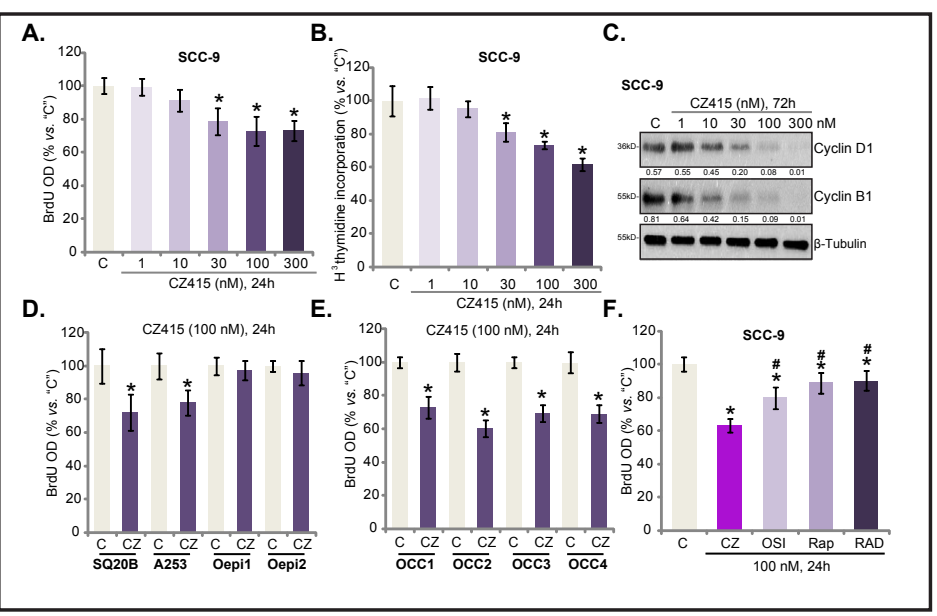

Fig. 2. CZ415 inhibits HNSCC cell proliferation. The established HNSCC cells (SCC-9, SQ20B and A253) (A-D, F), the primary human OCC cells ("OCC1-4 lines") (E) or the oral epithelial cells ("Oepi1/2 lines") (D) were treated with designated concentration of CZ415 ("CZ"), rapamycin (“Rap"), RAD001 (“RAD”) or OSI-027 (“OSI"), cells were further cultured for indicated time, and cell proliferation and expression of proliferation-associated proteins were tested by assays mentioned in the text. Cyclin D1 and Cyclin B1 expression were quantified and normalized to Tubulin (C). For each assay, $n=5 . * \mathrm{p}<0.05$ vs. group "C". " p $<0.05$ vs. CZ415 only (F). Experiments in this Fig. were repeated four times, and similar results were obtained. the mTOR kinase inhibitor OSI-027 [25] (Fig. 1F).

Collectively, these results suggest that CZ415 inhibits HNSCC cell survival.

\section{CZ415 inhibits HNSCC cell proliferation}

As described [12], the BrdU ELISA assay and $\left[\mathrm{H}^{3}\right]$ thymidine incorporation assay were performed to test cell proliferation. Results show that CZ415 dose-dependently inhibited 


\section{Cellular Physiology Cell Physiol Biochem 2018;46:676-686 and Biochemistry Publisned 10n/00488724 April05, $2018 \quad \begin{aligned} & \text { O 2018 The Author(s). Published by S. Karger AG, Basel } \\ & \text { www.karger.com/cpb }\end{aligned}$

SCC-9 cell proliferation (Fig. 2A and B). BrdU ELISA OD (Fig. 2A) and $\left[\mathrm{H}^{3}\right]$ thymidine (Fig. 2B) were significantly decreased after CZ415 (30-300 nM) treatment. Additionally, cyclin D1 and cyclin B1 were downregulated in CZ415-treated cells (Fig. 2C).

In SQ20B and A253 cells, BrdU incorporation was inhibited after CZ415 treatment as well (Fig. 2D). CZ415 was ineffective on BrdU incorporation in the oral epithelial cell ("Oepi1/2") (Fig. 2D). Significantly, BrdU ELISA OD was decreased by CZ415 in the primary HNSCC cells (Fig. 2E). Again, CZ415 was more efficient in suppressing SCC- 9 cell proliferation than rapamycin, RAD001 and OSI-027 (Fig. 2F). Collectively, these results show that CZ415 inhibits HNSCC cell proliferation.

\section{CZ415 blocks mTORC1/2 activation and inhibits ERK activation in HNSCC cells \\ CZ415 is a mTOR kinase} inhibitor [16, 17, 26]. mTOR signaling in CZ415-treated cells was tested. As shown, in SCC-9 cells, phosphorylation ("p-") of the mTORC1 substrate S6K1 (Ser-389) and the mTORC2 substrate AKT (Ser-473) were inhibited by CZ415 (Fig. 3A). p-AKT at

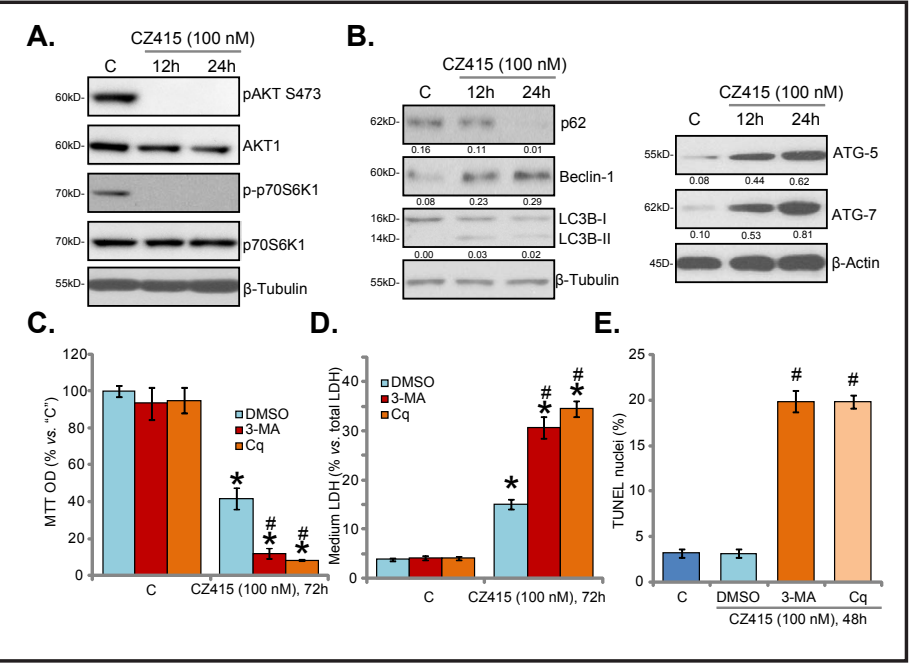

Fig. 4. Autophagy inhibition sensitizes CZ415-induced killing of SCC-9 cells. SCC-9 cells were treated with/out CZ415 (100 nM) for the indicated time, expression of listed proteins were tested by Western blotting assay (A and B). SCC-9 cells were pretreated with 3-methyladenine (3-MA, $10 \mathrm{mM}$ ) or chloroquine $(\mathrm{Cq}, 100 \mu \mathrm{M})$ for 1 hour, followed by CZ415 (100 nM) treatment for applied time; Cell viability (MTT assay, C), cell death (LDH release assay, D) and apoptosis (TUNEL assay, E) were tested. Blot data were quantified (A and B). For each assay, $n=5 .{ }^{*} \mathrm{p}<0.05$ vs. group "C" (C-E). " $\mathrm{p}<0.05$ vs. "DMSO" (0.1\%) (C-E). Experiments in this Fig. were repeated three times, and similar results were obtained.

Thr-308 was not significantly

affected (Fig. 3A). Importantly, CZ415 inhibited ERK activation, and p-ERK1/2 (T202/ Y204) level decreased in SCC-9 cells (Fig. 3A). The basal activation of mTORC1 (p-S6K1) and mTORC2 (p-AKT Ser-473) were high in the primary human OCC cells ("OCC-1/4"), but low in the oral epithelial cells ("Oepi1/2") (Fig. 3B). In the primary human OCC cells ("OCC1"), CZ415 blocked mTORC1 (p-S6K1) and mTORC2 (p-AKT Ser-473) activation, whiling inhibiting ERK activation (Fig. 3C). p-AKT at Thr-308 was again not affected by CZ415 (Fig. 3C). Conversely, 


\section{Cellular Physiology Cell Physiol Biochem 2018;46:676-686 \begin{tabular}{l|l} 
DOI: 10.1159/000488724 & and Biochemistry \\
Published online: April U5, 2018 & $\begin{array}{l}\text { 2018 The Author(s). Published by S. Karger AG, Basel } \\
\text { www.karger.com/cpb }\end{array}$
\end{tabular} \\ Xie et al.: CZ415 Inhibits Human HNSCC Cells}

CZ415 had only minor inhibition on mTORC1/2 and ERK in oral epithelial cells ("Oepi2", Fig. 3D). These might explain the in-effectiveness of the mTOR kinase inhibitor in epithelial cells (Fig. 1 and 2).

\section{Autophagy inhibition sensitizes CZ415-induced SCC-9 cell death}

AKT-mTOR in-activation can induce feedback autophagy activation, which serves as a chemo-resistance factor. Autophagy-associated proteins in CZ415-treated HNSCC cells were then tested. CZ415-induced mTORC1/2 inactivation in SCC-9 cells lasted for 12-24 hours (Fig. 4A). Significantly, CZ415 induced Beclin-1, ATG-5, and ATG-7 upregulation, light chain 3B (LC3B)-I to LC3B-II conversion and p62 degradation (Fig. 4B), indicating autophagy activation [22, 27, 28]. Two well-known autophagy inhibitors, 3-methyladenine (3-MA) [29], chloroquine (Cq) [30], were applied next. CZ415-induced SCC-9 cell viability reduction (Fig. 4C) and cell death (Fig. 4D) were significantly potentiated by 3-MA or Cq. Therefore, autophagy inhibition can sensitize CZ415-induced SCC-9 cell death. Intriguingly, SCC-9 cell apoptosis was only induced by CZ415 when combined with the autophagy inhibitors (Fig. 4E). Feedback autophagy activation could be the reason of non-apoptosis in CZ415-treated cells. Inhibition of autophagy can re-provoke SCC-9 cell. The autophagy inhibitors alone failed to affect cell survival and apoptosis (Fig. 4C-E).

\section{Beclin-1 knockdown sensitizes CZ415}

A shRNA method was utilized to knockdown Beclin-1, which is a key autophagy protein $[31,32]$. Two different Beclin-1-targeting shRNAs ("a/b"), with non-overlapping sequences, were from Dr. Jiang' [22]. A Western blotting assay confirm that both shRNAs induced significant Beclin-1 downregulation in SCC-9 cells (Fig. 5A). Consequently, CZ415-induced SCC-9 cell viability reduction (Fig. 5B) and cell death (Fig. 5C) were significantly potentiated. CZ415 induced apoptosis activation in Beclin-1-silenced SCC-9 cells (Fig. 5D). Beclin-1 shRNA alone had no significant effect on SCC-9 cell survival, death and apoptosis (Fig. 5BD). Therefore, Beclin-1 shRNA results confirm that autophagy activation is a key resistance factor of CZ415. In A253 cells (Fig. 5E) and the primary human OCC cells ("OCC1 line", Fig. 5F), the autophagy inhibitor 3-MA significantly potentiated CZ415-induced viability reduction. In contrast, CZ415 and 3-MA combination was non-cytotoxic to the epithelial cells ("Oepi1", Fig. 5G).

Fig. 5. Beclin-1 knockdown sensitizes CZ415. The SCC-9 cells, expressing Beclin-1-targeting shRNA ("a/b") or scramble control shRNA ("shSCR"), as well as the parental control SCC-9 cells ("Parental") were treated with/out CZ415 (100 nM) for applied time; Be-

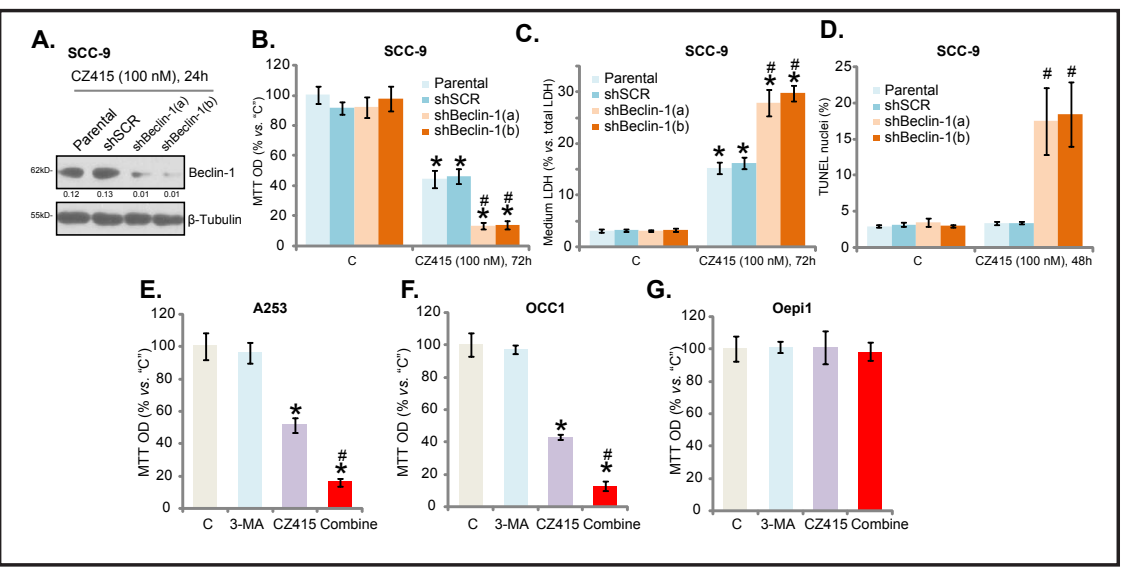
clin-1 expression

(A), cell viability (MTT assay, B), cell death (LDH release assay, C) and apoptosis (TUNEL assay, D) were tested. A253 cells (E), the primary human OCC cells ("OCC1") (F) or the primary human oral epithelial cells ("Oepi1") (G) were pretreated with 3-methyladenine (3-MA, $10 \mathrm{mM}$ ) for 1 hour, followed by CZ415 (100 $\mathrm{nM}$ ) treatment for 72 hours; Cell viability was tested by MTT assay. For each assay, $\mathrm{n}=5$. * $\mathrm{p}<0.05$ vs. group "C". ${ }^{*}$ p $<0.05$ vs. "shSCR" cells (B-D). ${ }^{*}$ p $<0.05$ vs. CZ415 only treatment (E-G). Experiments in this Fig. were repeated three times, and similar results were obtained. 


\section{Cellular Physiology Cell Physiol Biochem 2018;46:676-686

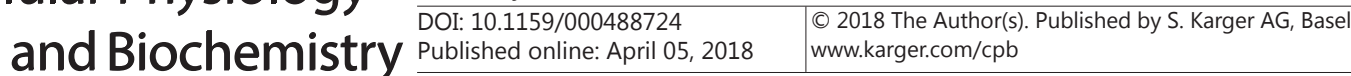 Xie et al.: CZ415 Inhibits Human HNSCC Cells}

Beclin-1 shRNA sensitizes CZ415-induced anti-tumor activity in vivo

At last, the CZ415's anti-tumor activity in vivo was tested. The SCC-9 tumor xenograft nude mice model was applied [12]. The tumor growth curve results, Fig. 6A, demonstrate that daily oral administration of CZ415 (20 mg/kg [16]) significantly inhibited growth of SCC-9 tumors with control scramble shRNA ("sh-C"). The estimated daily SCC-9 tumor growth (in $\mathrm{mm}^{3}$ per day, Fig. 6B) and tumor weights (at week-6, Fig. 6C) were both decreased after CZ415 treatment. The CZ415's activity in vivo was largely sensitized against tumors expressing Beclin-1 shRNA (Fig. 6A-C). Beclin-1 shRNA alone didn't affect SCC-9 tumor growth (Fig. 6A-C). The Mice body weight was not significantly different between the groups (Fig. 6D). When analyzing tumor tissue samples by a Western blotting assay, we show that activation of mTORC1 (p-S6K1), mTORC2 (p-AKT Ser-473) and ERK were inhibited by CZ415 (Fig. 6E). Beclin-1 expression was increased in CZ415-treated tumor tissues, blocked by Beclin-1 shRNA (Fig. 6E). An immunohistochemistry (IHC) staining assay demonstrates inhibition of p-S6K1 in CZ415-treated SCC-9 tumors (Fig. 6F).

Next, the primary human OCC cells (OCC-1 line) were inoculated via s.c. injection to the nude mice. Within 2-3 weeks, the xenograft tumors were established. Results in Fig. 6G demonstrate that the growth of the primary human OCC cells was significantly inhibited by CZ415 (20 mg/kg, daily) as well. CZ415 didn't affect the mice body weight (Fig. 6H). mTORC1 (p-S6K1), mTORC2 (p-AKT Ser-473) and ERK activation in tumor tissues were inhibited by CZ415 as well (Fig. 6I). Beclin-1 expression was increased, suggesting autophagy induction (Fig. 6I). These results together suggest that autophagy inhibition by Beclin-1 shRNA sensitizes CZ415-induced anti-tumor activity in vivo.

Fig. 6. Beclin-1 shRNA sensitizes CZ415-induced anti-tumor activity in vivo. The nude mice bearing SCC-9 tumors with Beclin-1 shRNA ("a") or scramble control shRNA ("sh-C") were administrated daily with CZ415 (20 mg/kg body weight, gavage); Tumor volumes (A) and mice body weights (D) were recorded every week for a total of 5 weeks; Estimated daily tumor growth was also calculated (B); At the end of experiment (Week6), SCC-9 tumors were isolated and weighted (C). At day-21, one tumor per group was isolated,

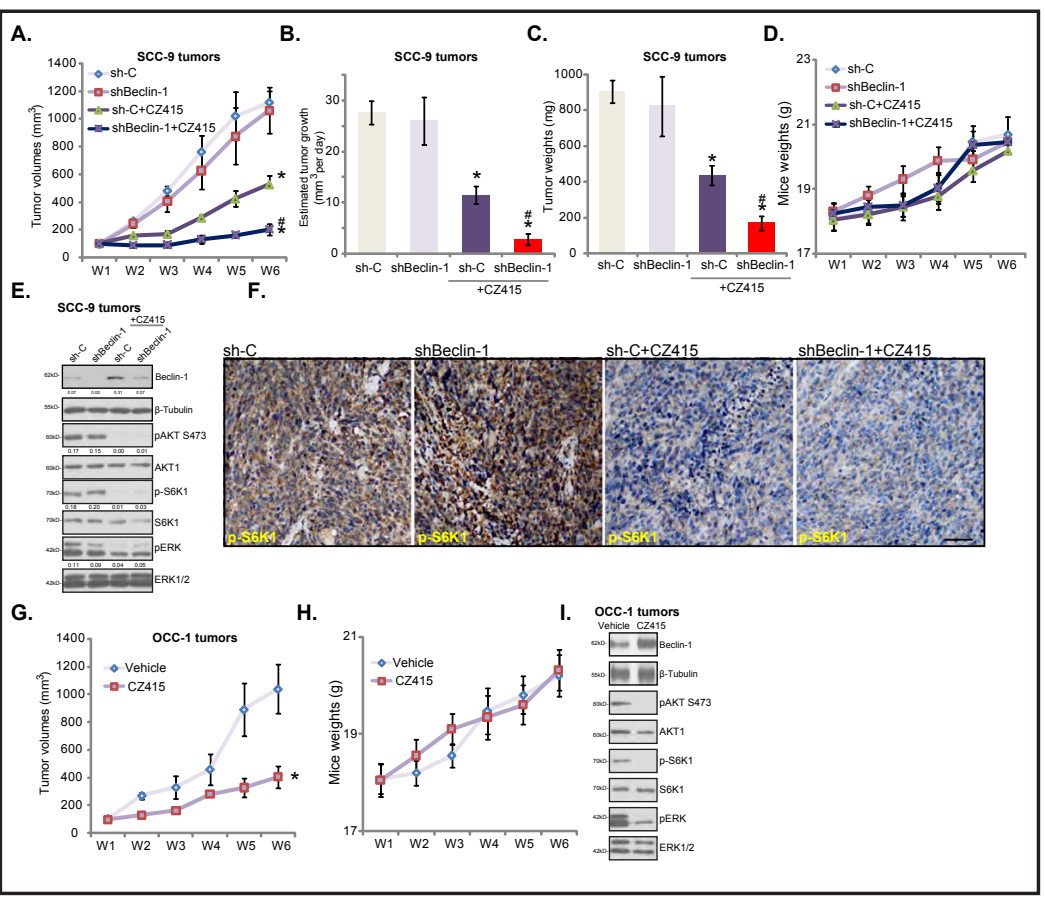
tumor tissue lysates were subjected to Western blotting assay of listed proteins (E) and IHC staining assay of p-S6K1 (F, bar= $100 \mu \mathrm{m}$ ). The nude mice bearing the primary human OCC cells (OCC-1 line) were administrated daily with CZ415 (20 mg/kg body weight, gavage) or vehicle control ("Saline"), tumor volumes (G) and mice body weights $(\mathrm{H})$ were recorded; At day-21, one tumor of each group was isolated, signalings were tested (I). Blot data were quantified (E). For each group, n=10 (mice). ${ }^{*} \mathrm{p}<0.05$ vs. group of "sh-C" only $(\mathrm{A}-\mathrm{C}) .{ }^{*} \mathrm{p}<0.05$ vs. "sh$\mathrm{C}+\mathrm{CZ415}$ " group (A-C). * p<0.05 vs. group of "Vehicle" (G). 


\section{Cellular Physiology Cell Physiol Biochem 2018;46:676-686 \\ \begin{tabular}{l|l} 
DOI: 10.1159/000488724 & a 2018 The Author(s). Published by S. Karger AG, Basel \\
www.karger.com/cpb
\end{tabular} \\ Xie et al.: CZ415 Inhibits Human HNSCC Cells}

\section{Discussion}

mTORC1 inhibitors, including rapamycin and its analogs, can have several limitations. Rapamycin binds to FKBP12, which indirectly and only partly inhibits mTORC1 activity [33]. mTORC1 inhibition can also lead to feedback activation of several key oncogenic signalings, including AKT and ERK $[13,34-36]$. The in vivo and clinical use of mTORC1 inhibitors is limited due to the poor solubility $[37,38]$. The most important of all is that mTORC1 inhibitors have no direct inhibition on mTORC2 activity [7].

Due to these drawbacks of mTORC1 inhibitors, recent research effects have developed "the second-generation of mTOR inhibitors" [37, 38]. These compounds, including OSI-027 [25, 39], AZD-8055 [40], AZD-2014 [18, 28] and XL388 [41], directly inhibit mTOR kinase to block activity of both mTORC1 and mTORC2 $[37,38]$. Here, we show that CZ415 blocked mTORC1 and mTORC2 activation, but failed to induce feedback AKT and ERK activation. CZ415 was more efficiently in killing HNSCC cells than the knonw mTORC1 inhibitors (rapamycin and RAD001).

The anti-HNSCC cell activity by CZ415 is even more potent than the mTOR kinase inhibitor OSI-027. It is possible that CZ415may have better efficiency in blocking mTOR [16] than OSI-027. It is possibly due to the co-current inhibition of ERK signaling by CZ415 as well. Another key advantage of CZ415 is its orally bioactivity. CZ415 oral administration inhibited growth of SCC- 9 cells and primary human OCC cells in the nude mice. These results, together with the fact that CZ415 is non-cytotoxic to oral epithelial cells, suggest that this novel mTOR kinase could be a novel and promising anti-HNSCC agent.

When autophagy is activated, cells actively degradate its own components (i.e. organelles and cell proteins), which provides nutrition and energy for survive [42-44]. In cancer cells, many anti-cancer agents could induce feedback autophagy activation [42-45]. Conversely, autophagy inhibition can sensitize the anti-cancer activity [42-45]. Activated mTOR shuts down autophagy. mTOR phosphorylates unc-51-like kinase 1 (ULK1) [46] and autophagyrelated protein 13 (ATG-13) [47] to inhibit autophagy initiation. mTOR inhibition, on the other hand, shall lead to autophagy induction [48-50]. Here, we show that CZ415 induced autophagy activation in HNSCC cells. Autophagy was evidenced by Beclin-1/ATG-5/ ATG7 upregulation, LC3B-I to LC3B-II conversion and p62 degradation. Conversely, autophagy inhibitors sensitized CZ415-induced anti-HNSCC cell activity, causing profound cell death and apoptosis.

Beclin-1 is a Bcl-2-interacting protein, it is the mammalian orthologue of the yeast protein Apg6/Vps30 [32, 51, 52]. Beclin-1 is required for autophagosome formation, also indispensable for autophagy initiation and progression [32]. Here, we show that shRNAmediated knockdown of Beclin-1 sensitized CZ415-induced anti-HNSCC cell activity. In vivo, CZ415-induced anti-tumor activity was further potentiated against Beclin-1-silenced SCC-9 tumors. These evidence suggests that Beclin-1-driven autophagy is the primary resistance factor of CZ415 in HNSCC cells.

\section{Conclusion}

Together, targeting mTOR by CZ415 inhibits HNSCC cell growth in vitro and in vivo. Inhibition of feedback autophagy can further sensitize CZ415 against HNSCC cells.

\section{Acknowledgements}

This work was generously supported by grants from the Wenzhou Science and Technology Bureau (Y20130260). The funders had no role in study design, data collection and analysis, decision to publish, or preparation of the manuscript.

All authors carried out all the experiments, participated in the design of the project conceived of the study, and participated in its design and coordination and helped to draft the manuscript. 


\section{Cellular Physiology Cell Physiol Biochem 2018;46:676-686 and Biochemistry Published \begin{tabular}{l|l} 
DOI: 10.1159/000488724 & $\begin{array}{l}\text { (c) } 2018 \text { The Author(s). Published by S. Karger AG, Basel } \\
\text { www.karger.com/cpb }\end{array}$
\end{tabular} Xie et al.: CZ415 Inhibits Human HNSCC Cells}

\section{Disclosure Statement}

The authors listed no competing interests.

\section{References}

1 Bozec A, Peyrade F, Fischel JL, Milano G: Emerging molecular targeted therapies in the treatment of head and neck cancer. Expert Opin Emerg Drugs 2009;14:299-310.

-2 Goerner M, Seiwert TY, Sudhoff H: Molecular targeted therapies in head and neck cancer--an update of recent developments. Head Neck Oncol 2010;2:8.

-3 Sano D, Fooshee DR, Zhao M, Andrews GA, Frederick MJ, Galer C, Milas ZL, Morrow PK, Myers JN: Targeted molecular therapy of head and neck squamous cell carcinoma with the tyrosine kinase inhibitor vandetanib in a mouse model. Head Neck 2011;33:349-358.

- Peng Y, Zhou Y, Cheng L, Hu D, Zhou X, Wang Z, Xie C, Zhou F: The anti-esophageal cancer cell activity by a novel tyrosine/phosphoinositide kinase inhibitor PP121. Biochem Biophys Res Commun 2015;465:137144.

-5 Freudlsperger C, Burnett JR, Friedman JA, Kannabiran VR, Chen Z, Van Waes C: EGFR-PI3K-AKT-mTOR signaling in head and neck squamous cell carcinomas: attractive targets for molecular-oriented therapy. Expert Opin Ther Targets 2011;15:63-74.

6 Molinolo AA, Marsh C, El Dinali M, Gangane N, Jennison K, Hewitt S, Patel V, Seiwert TY, Gutkind JS: mTOR as a molecular target in HPV-associated oral and cervical squamous carcinomas. Clin Cancer Res 2012;18:2558-2568.

7 Amornphimoltham P, Patel V, Sodhi A, Nikitakis NG, Sauk JJ, Sausville EA, Molinolo AA, Gutkind JS: Mammalian target of rapamycin, a molecular target in squamous cell carcinomas of the head and neck. Cancer Res 2005;65:9953-9961. Saxton RA, Sabatini DM: mTOR Signaling in Growth, Metabolism, and Disease. Cell 2017;168:960-976. Wei J, Jiang H, Gao H, Wang G: Blocking Mammalian Target of Rapamycin (mTOR) Attenuates HIF-1alpha Pathways Engaged-Vascular Endothelial Growth Factor (VEGF) in Diabetic Retinopathy. Cell Physiol Biochem 2016;40:1570-1577.

10 Yang H, Xiong X, Wang X, Yin Y: Mammalian Target of Rapamycin Signaling Pathway Changes with Intestinal Epithelial Cells Renewal Along Crypt-Villus Axis. Cell Physiol Biochem 2016;39:751-759.

11 Han C, Wei S, Song Q, He F, Xiong X, Wan H, Liu D, Ye F, Liu H, Li L, Xu H, Du X, Kang B, Zeng X: Insulin Stimulates Goose Liver Cell Growth by Activating PI3K-AKT-mTOR Signal Pathway. Cell Physiol Biochem 2016;38:558-570.

12 Xie J, Li Q, Ding X, Gao Y: GSK1059615 kills head and neck squamous cell carcinoma cells possibly via activating mitochondrial programmed necrosis pathway. Oncotarget 2017;10.18632/oncotarget.15135 Dancey J: mTOR signaling and drug development in cancer. Nat Rev Clin Oncol 2010;7:209-219. Sabatini DM: mTOR and cancer: insights into a complex relationship. Nat Rev Cancer 2006;6:729-734. Zhang YM, Zhang ZQ, Liu YY, Zhou X, Shi XH, Jiang Q, Fan DL, Cao C: Requirement of Galphai1/3-Gab1 signaling complex for keratinocyte growth factor-induced PI3K-AKT-mTORC1 activation. J Invest Dermatol 2015;135:181-191.

16 Cansfield AD, Ladduwahetty T, Sunose M, Ellard K, Lynch R, Newton AL, Lewis A, Bennett G, Zinn N, Thomson DW, Ruger AJ, Feutrill JT, Rausch O, Watt AP, Bergamini G: CZ415, a Highly Selective mTOR Inhibitor Showing in vivo Efficacy in a Collagen Induced Arthritis Model. ACS Med Chem Lett 2016;7:768773.

17 Yin G, Fan J, Zhou W, Ding Q, Zhang J, Wu X, Tang P, Zhou H, Wan B, Yin G: ERK inhibition sensitizes CZ415induced anti-osteosarcoma activity in vitro and in vivo. Oncotarget 2017;8:82027-82036.

18 Li Y, Cui JT: Inhibition of Bcl-2 potentiates AZD-2014-induced anti-head and neck squamous cell carcinoma cell activity. Biochem Biophys Res Commun 2016;477:607-613.

19 Cao C, Huang X, Han Y, Wan Y, Birnbaumer L, Feng GS, Marshall J, Jiang M, Chu WM: Galpha(i1) and Galpha(i3) are required for epidermal growth factor-mediated activation of the Akt-mTORC1 pathway. Sci Signal 2009;2:ra17. 


\section{Cellular Physiology Cell Physiol Biochem 2018;46:676-686 and Biochemistry Published onl004ne: April 05, $2018 \quad \begin{aligned} & \text { DOI 1018 2018 The Author(s). Published by S. Karger AG, Basel } \\ & \text { www.karger.com/cpb }\end{aligned}$ \\ Xie et al.: CZ415 Inhibits Human HNSCC Cells}

20 Ji F, Mao L, Liu Y, Cao X, Xie Y, Wang S, Fei H: K6PC-5, a novel sphingosine kinase 1 (SphK1) activator, alleviates dexamethasone-induced damages to osteoblasts through activating SphK1-Akt signaling. Biochem Biophys Res Commun 2015;458:568-575.

-21 Cao C, Rioult-Pedotti MS, Migani P, Yu CJ, Tiwari R, Parang K, Spaller MR, Goebel DJ, Marshall J: Impairment of TrkB-PSD-95 signaling in Angelman syndrome. PLoS Biol 2013;11:e1001478.

-22 Zhang Q, Yang M, Qu Z, Zhou J, Jiang Q: Autophagy prevention sensitizes AKTi-1/2-induced antihepatocellular carcinoma cell activity in vitro and in vivo. Biochem Biophys Res Commun 2016;480:334340.

-23 Chen MB, Ji XZ, Liu YY, Zeng P, Xu XY, Ma R, Guo ZD, Lu JW, Feng JF: Ulk1 over-expression in human gastric cancer is correlated with patients' T classification and cancer relapse. Oncotarget 2017;8:33704-33712.

$\checkmark 24$ Awada A, Cardoso F, Fontaine C, Dirix L, De Greve J, Sotiriou C, Steinseifer J, Wouters C, Tanaka C, Zoellner U, Tang P, Piccart M: The oral mTOR inhibitor RAD001 (everolimus) in combination with letrozole in patients with advanced breast cancer: results of a phase I study with pharmacokinetics. Eur J Cancer 2008;44:8491.

25 Bhagwat SV, Gokhale PC, Crew AP, Cooke A, Yao Y, Mantis C, Kahler J, Workman J, Bittner M, Dudkin L, Epstein DM, Gibson NW, Wild R, Arnold LD, Houghton PJ, Pachter JA: Preclinical characterization of OSI027, a potent and selective inhibitor of mTORC1 and mTORC2: distinct from rapamycin. Mol Cancer Ther 2011;10:1394-1406.

-26 Zhang W, Chen B, Zhang Y, Li K, Hao K, Jiang L, Wang Y, Mou X, Xu X, Wang Z: The anti-hepatocellular carcinoma cell activity by a novel mTOR kinase inhibitor CZ415 Biochem Biophys Res Commun 2017;487:494-499.

27 Zhou C, Gu J, Zhang G, Dong D, Yang Q Chen MB, Xu D: AMPK-autophagy inhibition sensitizes icaritininduced anti-colorectal cancer cell activity. Oncotarget 2017;8:14736-14747.

-28 Zheng B, Mao JH, Qian L, Zhu H, Gu DH, Pan XD, Yi F, Ji DM: Pre-clinical evaluation of AZD-2014, a novel mTORC1/2 dual inhibitor, against renal cell carcinoma. Cancer Lett 2015;357:468-475.

29 Seglen PO, Gordon PB: 3-Methyladenine: specific inhibitor of autophagic/lysosomal protein degradation in isolated rat hepatocytes. Proc Natl Acad Sci U S A 1982;79:1889-1892.

-30 Schonewolf CA, Mehta M, Schiff D, Wu H, Haffty BG, Karantza V, Jabbour SK: Autophagy inhibition by chloroquine sensitizes HT-29 colorectal cancer cells to concurrent chemoradiation. World J Gastrointest Oncol 2014;6:74-82.

-31 McCoy F, Hurwitz J, McTavish N, Paul I, Barnes C, O’Hagan B, Odrzywol K, Murray J, Longley D, McKerr G, Fennell DA: Obatoclax induces Atg7-dependent autophagy independent of beclin-1 and BAX/BAK. Cell Death Dis 2010;1:e108.

32 Fu LL, Cheng Y, Liu B: Beclin-1: autophagic regulator and therapeutic target in cancer. Int J Biochem Cell Biol 2013;45:921-924.

-33 Schreiber KH, Ortiz D, Academia EC, Anies AC, Liao CY, Kennedy BK: Rapamycin-mediated mTORC2 inhibition is determined by the relative expression of FK506-binding proteins. Aging Cell 2015;14:265-273.

-34 Sun SY: mTOR kinase inhibitors as potential cancer therapeutic drugs. Cancer Lett 2013;340:1-8.

-35 Lamming DW, Ye L, Sabatini DM, Baur JA: Rapalogs and mTOR inhibitors as anti-aging therapeutics. J Clin Invest 2013;123:980-989.

-36 Easton JB, Houghton PJ: mTOR and cancer therapy. Oncogene 2006;25:6436-6446.

-37 Vilar E, Perez-Garcia J, Tabernero J: Pushing the envelope in the mTOR pathway: the second generation of inhibitors. Mol Cancer Ther 2011;10:395-403.

-38 Zhou HY, Huang SL: Current development of the second generation of mTOR inhibitors as anticancer agents. Chin J Cancer 2012;31:8-18.

-39 Chen B, Xu M, Zhang H, Xu MZ, Wang XJ, Tang QH, Tang JY: The Antipancreatic Cancer Activity of OSI-027, a Potent and Selective Inhibitor of mTORC1 and mTORC2. DNA Cell Biol 2015;34:610-617.

40 Liu M, Gu P, Guo W, Fan X: C6 ceramide sensitizes the anti-hepatocellular carcinoma (HCC) activity by AZD8055, a novel mTORC1/2 dual inhibitor. Tumour Biol 2016;37:11039-11048.

41 Zhu YR, Zhou XZ, Zhu LQ, Yao C, Fang JF, Zhou F, Deng XW, Zhang YQ: The anti-cancer activity of the mTORC1/2 dual inhibitor XL388 in preclinical osteosarcoma models. Oncotarget 2016;7:49527-49538.

42 Kondo Y, Kanzawa T, Sawaya R, Kondo S: The role of autophagy in cancer development and response to therapy. Nat Rev Cancer 2005;5:726-734. 


\section{Cellular Physiology Cell Physiol Biochem 2018;46:676-686 and Biochemistry Publisned 10,00488724, $2018 \quad \begin{aligned} & \text { O 2018 The Author(s). Published by S. Karger AG, Basel } \\ & \text { www.karger.com/cpb }\end{aligned}$ \\ Xie et al.: CZ415 Inhibits Human HNSCC Cells}

-43 Janku F, McConkey DJ, Hong DS, Kurzrock R: Autophagy as a target for anticancer therapy. Nat Rev Clin Oncol 2011;8:528-539.

44 Rubinsztein DC, Codogno P, Levine B: Autophagy modulation as a potential therapeutic target for diverse diseases. Nat Rev Drug Discov 2012;11:709-730.

45 Marino G, Niso-Santano M, Baehrecke EH, Kroemer G: Self-consumption: the interplay of autophagy and apoptosis. Nat Rev Mol Cell Biol 2014;15:81-94.

-46 Kim J, Kundu M, Viollet B, Guan KL: AMPK and mTOR regulate autophagy through direct phosphorylation of Ulk1. Nat Cell Biol 2011;13:132-141.

-47 Jung CH, Jun CB, Ro SH, Kim YM, Otto NM, Cao J, Kundu M, Kim DH: ULK-Atg13-FIP200 complexes mediate mTOR signaling to the autophagy machinery. Mol Biol Cell 2009;20:1992-2003.

48 Moscat J, Diaz-Meco MT: Feedback on fat: p62-mTORC1-autophagy connections. Cell 2011;147:724-727.

-49 Li H, Jin X, Zhang Z, Xing Y, Kong X: Inhibition of autophagy enhances apoptosis induced by the PI3K/AKT/ mTor inhibitor NVP-BEZ235 in renal cell carcinoma cells. Cell Biochem Funct 2013;31:427-433.

50 Altman JK, Szilard A, Goussetis DJ, Sassano A, Colamonici M, Gounaris E, Frankfurt O, Giles FJ, Eklund EA, Beauchamp EM, Platanias LC: Autophagy is a survival mechanism of acute myelogenous leukemia precursors during dual mTORC2/mTORC1 targeting. Clin Cancer Res 2014;20:2400-2409.

51 Liang XH, Jackson S, Seaman M, Brown K, Kempkes B, Hibshoosh H, Levine B: Induction of autophagy and inhibition of tumorigenesis by beclin 1. Nature 1999;402:672-676.

-52 Scarlatti F, Maffei R, Beau I, Codogno P, Ghidoni R: Role of non-canonical Beclin 1-independent autophagy in cell death induced by resveratrol in human breast cancer cells. Cell Death Differ 2008;15:1318-1329. 